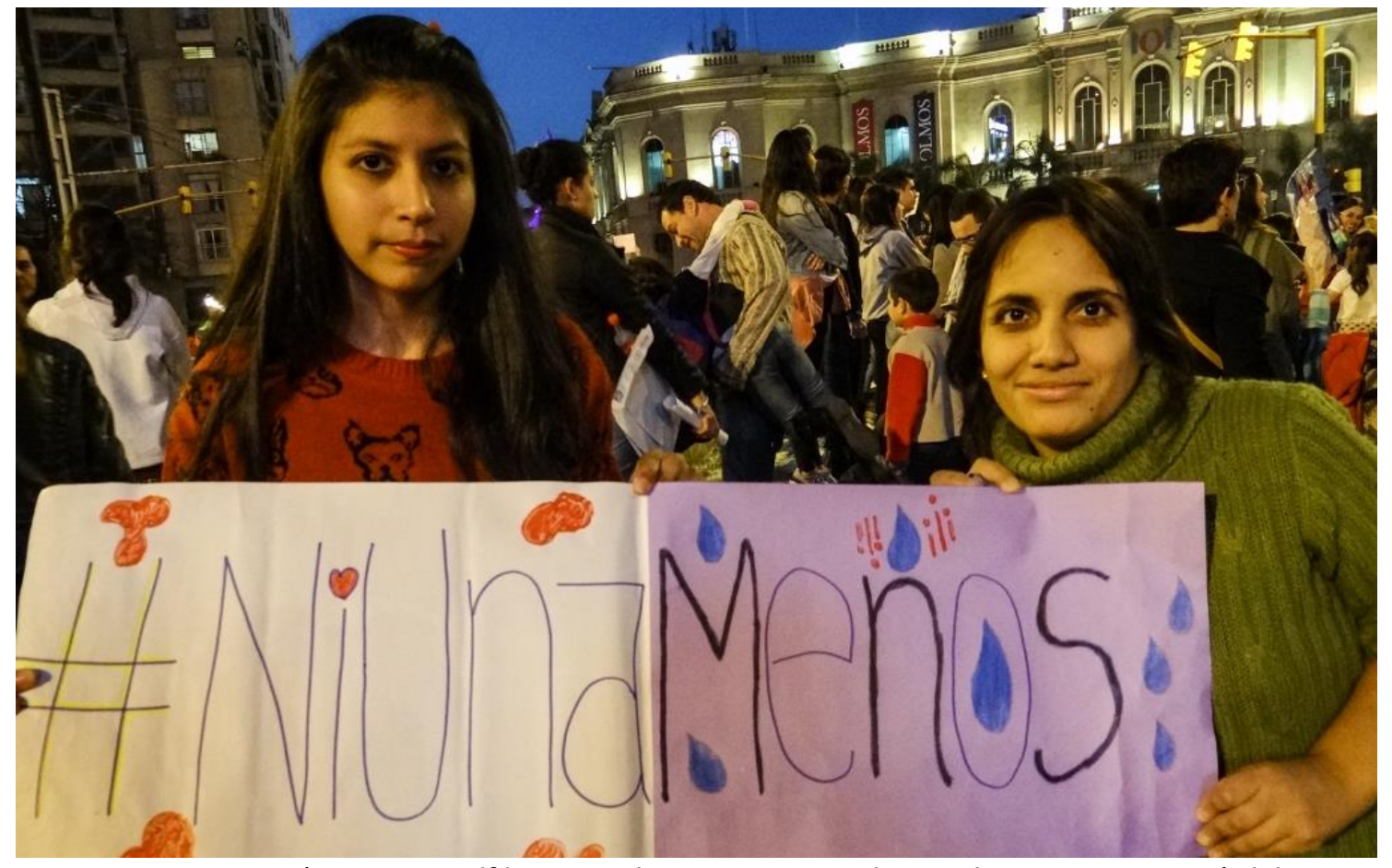

FOTOS: Irina Morán - Revista Alfilo - Periodista Feminista. Militante de Ni Una Menos Córdoba y Mujeres por un parto Respetado 


\section{EPISTEMOLOGÍAS ADVERSAS}

Andrea Analía Benavidez ${ }^{1}$

Resumen: Este ensayo propone reflexionar de manera crítica sobre educación superior y la ausencia de estudios feministas a la enseñanza de la epistemología. Los movimientos de las mujeres y la diversidad sexual han impuesto una agenda pública que ha atravesado los ámbitos académicos y los debates teóricos actuales. Resulta notable que, a pesar de la prolífera producción de epistemologías feministas, la inserción en las asignaturas universitarias sea exigua. Los ámbitos específicos de epistemología sostienen concepciones arraigadas en tradiciones científicas que son resistentes a incorporar los nuevos marcos de referencia teóricos para la formación universitaria de grado. Examinar algunas de las limitaciones y aperturas entorno a estas cuestiones guía el recorrido de este trabajo.

Palabras-clave: Epistemología. Feminismo. Educación superior.

\section{EPISTEMOLOGIAS ADVERSAS}

Resumo: Este ensaio propõe uma reflexão crítica sobre o ensino superior e a ausência de estudos feministas no ensino da epistemologia. Os movimentos de mulheres e a diversidade sexual impuseram uma agenda pública que abrangeu áreas acadêmicas e debates teóricos atuais. É notável que, apesar da prolífica produção de epistemologias feministas, a inserção nos sujeitos universitários seja escassa. As áreas específicas da epistemologia apóiam concepções enraizadas em tradições científicas que são resistentes a incorporar os novos referenciais teóricos para o ensino universitário de graduação. Examinar algumas das limitações e aberturas em torno dessas questões orienta o curso deste trabalho.

Palavras-chave: Epistemologia. Feminismo. Ensino superior.

\section{INTRODUCCIÓN}

En este ensayo propongo pensar en las epistemologías en sentido geopolítico. También, buscar las tensiones en relación con las necesarias reconfiguraciones de las disciplinas académicas que ordenan los contenidos y los conocimientos en las aulas en torno a las epistemes. Pienso en nuevos modos de enseñar y aprender eso que llamamos epistemología y propongo reflexionar sobre la permanencia de los contenidos que desde el siglo XIX se agrupan bajo esa etiqueta. Las aulas han cambiado, el sistema académico también, los/las estudiantes se suman a las universidades con expectativas y desencantos. Es notable que la producción de bibliografía escrita y publicada por mujeres es insigne (Spivak, 1988; Mendoza, 2010; Bidaseca, 2010; Campagnolli, 2018; Stagnaro, 2015) pero también es llamativa la ausencia en las propuestas curriculares y planificaciones de cátedra de materiales con esos aportes específicos. Me pregunto ¿por qué los muros siguen presentes hacia la producción epistemológica de las mujeres a

\footnotetext{
${ }^{1}$ Licenciatura en filosofía. Centro: Universidade Nacional de San Juan(UNSJ), Argentina. Máster En Pensamiento Contemporáneo (Investigação). Centro: Universidade de Murcia (UM). Departamento de Filosofia. Doctorado En Estudios Literarios. Calificação: Apto, Cum Laude. Centro: Universidade de Alicante (UA). Departamento de Filologia Espanhola, lingüística geral e teoria daliteratura.
}

Momento: diálogos em educação, E-ISSN 2316-3100, v. 28, n. 3, p. 113-131, set./dez, 2018. 
pesar de la legitimidad en la producción de las autoras? La bibliografía fundamental con la que se enseña epistemología en los claustros permanece inalterable y deudora de perspectivas clásicas de la epistemología. Las excepciones están matizada con leves variaciones provenientes de la sociología del conocimiento. No obstante, la perspectiva de género tiene una notable incidencia en la academia actual, pero en muchos casos ocupa el espacio de lo "alternativo" cuando no el de las fronteras. En caso que siga asumiéndose que la bibliografía de lectura fundamental no incluye los aportes de género en su variedad de matices, entonces no se deja de abonar lo que estamos pensando como condiciones configuradoras de heridas epistémicas feministas (Benavidez, A; Guerra Pérez M., 2017). El conocimiento y las instituciones que lo sustentan no son neutras, tienen género y dejan huellas profundas en los/las estudiantes y también en docentes. Algunas de esas huellas son dolorosas y no favorecen la edificación plural del conocimiento epistemológico. Hay una serie de preguntas nuevas que necesitan ser formuladas para pensar otras tramas de conocimientos posibles y sobre estas sendas es necesarios avanzar. Una pregunta para invitar al juego es considerar qué significado adquiere el "contexto de descubrimiento" cuando es pensado por la perspectiva feminista. Otra pregunta es cómo es posible abandonar las relaciones entre sujeto, objeto y condiciones de posibilidad para el conocimiento expuestas por I. Kant (2009).

\section{LA TIERRA QUE PISAMOS Y OTROS CONTEXTOS}

La tierra que pisamos. El giro feminista en las epistemologías abrió una nueva vía para pensar las condiciones de producción del conocimiento. Hablar de contextos requiere ajustar a la medida humana unos parámetros que fueron establecidos en orden a la desmesura de la racionalidad propia de la modernidad. La tierra que pisamos, el aire que respiramos y las consecuencias de las acciones que emprendemos atravesaron las epistemes a partir de estas formas de rechazar la idea de neutralidad científica en relación con la naturaleza. Algunos momentos de epistemes adversas se tramaron en las aulas de la Universidad Nacional de San Juan durante el 2017. Una de ellas fue la conferencia inaugural en las Jornadas de Ecología Política de Horacio Machado Aráoz donde, a propósito del lugar que ocupa la Ecología Política en la historia de la epistemología, decía que este saber "desintegra esa frontera disciplinar establecida entre las ciencias sociales y las ciencias naturales que nos impide, no solamente conocer qué 
es la naturaleza, sino también nos impide comprender cuál es el lugar de lo humano en la naturaleza" (Machado Aráoz, H. 2017, p. 14). Esta conferencia de inicio tuvo su correlato con la de cierre pronunciada por Claudia Korol "Cuerpos y territorios. Las mujeres en la defensa de la vida diversa y de la libertad" (Korol, C., 2017) Otro momento de episteme adversa, que tuvo lugar en las aulas durante el mismo año, fue la publicación de los dossiers "Epistemologías-Metodologías críticas" y "Extractivismos" (Número 9 y 10 de RevIISE) al que siguió un conversatorio denominado "Viento sur"2 donde se debatió sobre los ejes trabajados en ambos números de la revista. La poética del título "viento sur" con la que se convocó al diálogo y se ocuparon las aulas juega con la semántica del enclave geopolítico que se discute en los trabajos, pero también es un contrapunto con el viento zonda propio de la región. La episteme adversa que fue hilándose en esas tramas resultó en una posición fuerte de discursos contrahegemónicos que durante el 2017 interpelaron a los espacios académicos institucionales locales. El viento sur trae descanso cuando llega luego del viento zonda, el frío sigue al calor y modera la presión ambiental. Las cuestiones ambientales, en este caso, funcionaron como metáforas cuyas semánticas tienen ecos en los contextos geopolíticos en los que se dieron las publicaciones y el conversatorio. El viento sur lleva un mensaje territorial hacia otras latitudes nord-centrales de Nuestra América para sumar discusiones que están abriéndose a medida que las epistemologías feministas profundizan en las preguntas que estos nuevos vientos traen al campo académico. En la misma línea otro matiz de episteme adversa dejó la evocación que Machado Aráoz hizo en su conferencia y que tanto nos identifica con la dependencia colonial "Ese grito "itierra!", hay que decir, fue el primer grito moderno, el primer grito propiamente moderno. Fue el primer acto de sacrilegio que echa a andar un proceso de deshumanización mundializada" (Machado Aráoz, H. 2017, p. 19). Esa tierra vista por el mercader, nos ha legado una visión de "descubrimiento" propia de la lógica expansionista euorocentrada. No es la misma tierra evocada por Claudia Korol para dar cierre a unos días en los que las discusiones sobre los conflictos territoriales, tramas de resistencia y presencia de mujeres en lugares de coyuntura política en torno a la naturaleza y el uso de ella, fueron el foco de las exposiciones. Una manera de pensar en las epistemes adveras es ver el gesto contrahegemónico que inauguran cuando se abren paso desde los márgenes de las tradiciones en torno a la naturaleza y la forma en la que las

\footnotetext{
${ }^{2}$ Conversatorio Viento Sur. Instituto de Investigaciones Socioeconómicas, FACSO, UNSJ. 7 y 8 de
} noviembre de 2017.

Momento: diálogos em educação, E-ISSN 2316-3100, v. 28, n. 3, p. 113-131, set./dez, 2018. 
construcciones sobre el conocimiento científico se presentan. Éstas van de las periferias al centro de las discusiones, porque descentran los argumentos tradicionales sobre el contexto de justificación del conocimiento. Luego de la irrupción del movimiento feminista en el campo académico, no resulta tan sencillo integrar las fases que usualmente se mencionan, la misma categorización de "contexto de descubrimiento" se agrieta porque deja ver la relación entre el lenguaje, el conocimiento y la conceptualización que los configura.

Las semánticas que evocan la tierra, de la madre tierra, la naturaleza envilecida por el poder colonial y defendida por las cosmovisiones propias de Abya Yala se tornan epistemes adversas aún para los propios movimientos feministas porque no dejan piedra sin remover para ver qué hay debajo y dan cuenta de posiciones epistémicas alternas y enérgicas "Las mujeres de Abya Yala construyen modernidades alternativas al colonialismo europeo y la victimización de las colonizadas a la que las relegan las feministas blancas" (Gargallo, 2015, p. 51).

\section{LA VOZ QUE HABLA Y LOS CUERPOS EN LAS EPISTEMOLOGÍAS}

La colonialidad sigue estando en nuestras instituciones académicas y convive de manera incómoda con el desplazamiento que ha producido el giro latinoamericano enunciado entre otros autores por De Sousa (2009); Castro Gómez (1998); Lander, E. (2010); Mignolo, W. (2010). Cuando nos encontramos en el aula y ofrecemos un programa de estudios para el semestre estamos operando una acción política que irrumpe en la expectativa de estudiantes que están ahí en estado de espera. La interrelación entre las personas, en un espacio áulico, reconfigura el proceso de aprendizaje. Quién habla sobre un determinado tema centra el eje epistémico porque sostiene una posición discursiva. "El habla, la escritura y los sistemas de signos de distinto tipo, tanto como su conceptualización - con la distribución disciplinar del saber que las formalizan -, integran un conjunto de relaciones por las que la colonización se hace efectiva" (Palermo, Z., 2007, p. 299). Es necesario hablar de los/las autoras que han escrito sobre los temas que aparecen descriptos en las planificaciones. También ayuda a la comprensión de los temas mostrar los recorridos académicos y geopolíticos de quienes funcionan como argumentos de autoridad en esas tramas de saberes. En la planificación de las asignaturas hay temas, hay problemas disciplinares, hay enfoques, hay personas que han pensado en todas esas dimensiones y que además han publicado 
sobre ello. Si mostramos los contextos de enunciación desde donde emergen esos problemas es posible que los y las estudiantes se aproximen a ideas sostenidas por autores y no sólo a temas/problemas aislados que han constituido el acervo disciplinar. La neutralidad científica se construye borrando el contexto además del suelo que se pisa y esa es una de las formas en la que el aprendizaje incide en la configuración de conocimientos. La interrelación entre las personas en un espacio áulico reconfigura el proceso de aprendizaje de acuerdo a las dimensiones que son opacadas o ponderadas en el discurso que dentro de ese entramado donde confluye la episteme. La voz que habla, el cuerpo que escucha, todo lo que se vehicula en ese intercambio no siempre es feliz. En cierto sentido, cuando se excluye de las asignaturas de epistemología perspectivas plurales que rompan con la ilusión moderna de unicidad científica; quizás en cierto modo se contribuye a la construcción de obstáculos epistemológicos (Bachelard, 1995). Situando los saberes fuera de ese espacio que se habita, esas palabras que son dichas y oídas en el aula no encuentran sentidos fuera de las tramas disciplinares. Insistir en la ausencia de acciones para modificar los contenidos en las asignaturas de epistemología y sostener la tradición epistemológica ligada al pensamiento científico moderno promueve la producción de epitsemcidio (De Sousa Santos, 2009). Estas reflexiones por las que derivo han sido posibles dada la conjunción de los giros epistémicos y feministas. También me han abierto grandes interrogantes las incomprensión de los/las estudiantes que durante años he tenido oportunidad de conocer y que han expresado de muy diversas maneras sus malestares y momentos felices en sus intentos siempre complejo de apropiación de pensamiento crítico.

Reichenbach H. (1938) clasificó el contexto de descubrimiento y contexto de justificación para la producción de conocimiento científico; Klimovsky G. (1995) sumó el contexto de aplicación. Desde la perspectiva "neutral" se impugna el contexto de descubrimiento como válida porque se piensa que todo lo que haya confluido para que una teoría o idea científica pueda ser formulada no es relevante. Se objeta que las condiciones personales y los factores psicológicos, políticos, sociales, etc., si bien funcionan como condiciones de posibilidad no cooperan para validar un conocimiento nuevo. En cambio, el contexto de justificación es percibido como el único certero porque la validación lógica-metodológica es dadora de verdad. El contexto de aplicación remite a los modos en los que el conocimiento será usufructuado. Las discusiones sobre las condiciones de aplicación están siendo discutidas por diferentes autores/as donde se toman en cuenta otros factores que inciden en los modos en los que 
la ciencia es puesta en valor dentro de esa tensión universal/particular, global/local como lo expone Stangnaro (2016),

De tal modo le concedió a la distinción histórica entre "ciencia básica" $\mathrm{y}$ "ciencia aplicada" un efecto esquematizante y formador, pero a su vez irrelevante a la hora de hacer elecciones temáticas en el marco de la práctica científica local. En su lugar, lo que surgió como determinante fue la capacidad restringida para competir local o globalmente (Stangnaro, A. 2016, p. 287)

A pesar de las diferencias entre Reichebach y Klimovsky, en sus trabajos se enuncian tres contextos que ocupan un lugar en la enseñanza de la epistemología general de nuestras universidades. Según se trate de ciencias exactas o de ciencias sociales los tres contextos pueden ser expuesto de manera diferente aunque recurrentes y el proceso de enseñanza-aprendizaje producirá epistemes desancladas a la disciplina específica de los contenidos curriculares. En estas construcciones de conocimiento científico, a través de esta forma tradicional de epistemología, las mujeres habrán quedado impugnadas por varias vías. No hay nombres de mujeres que se hayan ocupado de la producción de conocimiento, de la epistemología tradicional, ni que sean científicas reconocidas en este canon. Vale la pena distinguir entre los sujetos de conocimiento que donde las mujeres han sido sistemáticamente omitidas y la invisibilización de la producción de conocimientos que esas mujeres han producido. El androcentrismo y el patriarcado que se hace presente en las instituciones han potenciado la construcción de muros que inhiben la inclusión de autoras que abordan cuestiones epistemológicas. Ellas han quedado borradas o invisibilizadas. Esta es una de las formas en la que se produce heteronormatividad en las aulas de la que nos hablan muchas mujeres en bibliografías feministas y que desenfocan los modos hegemónicos de pensar el conocimiento científico. Las mujeres sabemos de esto porque hemos leído por fuera del canon en el que nos hemos educado en las academias. Las aulas están condicionadas por los saberes tradicionales y los/las docentes sostienen reproductivamente lo que la academia estructura como tal, aún en la disidencia. En esta forma en la que la epistemología clásica es enseñada, lo adverso es lo que nos permite mirar con mayor atención y sospecha a esos contextos que en principio aparecen separados en meticuloso procedimiento analítico. Desde hace más de dos décadas estas cuestiones vienen siendo advertidas y expuestas, pero es lento el proceso de cambio de la cultura académica. Zulma Palermo (2007) entre otras docentes e investigadoras se han ocupado de pensar en estos temas: "La contradicción entre lo que se dice y lo que 
se hace se erige como uno de los mayores obstáculos para producir al menos un principio de cambio en los procesos de producción de conocimiento, aun en aquellos actores que tienen más conciencia del nivel de colonización intelectual dentro del que realizan su práctica”. (Palermo, 2007, p. 303).

\section{EL MURO EN LAS AULAS}

La metáfora del techo de cristal y la de suelo pegajoso son evocadas (Torres González, O., Pau, B. 2011) para mencionar los obstáculos con los que las mujeres nos encontramos en las academias en su rol de productoras de conocimiento. Podemos incorporar una imagen más a esas semánticas de los obstáculos: el muro en las aulas. El muro en las aulas es una metáfora que veo operativa para pensar las barreras inmóviles que se interponen cuando se intenta discutir el canon en las áreas donde se enseñan contenidos de epistemología. La bibliografía producida por mujeres que piensan acerca del conocimiento es abundante y sólida pero la vemos enmarcada en espacios destinados a las teorías feministas. Incluso cuando se las enuncia en las planificaciones como perspectiva de género son sospechadas de no estar dando cuenta de los problemas que la epistemología clásica considera valiosos para la producción de pensamiento crítico sobre el conocimiento científico y la ampliación de los contenidos que son tomados en cuenta "La colonización también de nuestra episteme es un dato que permea el pensamiento feminista del Sur" (Bidaseca, 2014, p. 587).

Hay al menos dos modos de pensar el contexto en la enseñanza de las epistemologías, el que tiene connotaciones geopolíticas y el que sitúa la enseñanza en un área disciplinar Una institución se torna adversa cuando que prescribe autores, temas y problemas sin atender al contexto disciplinar en que se dictan las epistemologías. Es esa misma adversidad la que confluye para mantener un estado inalterable y da legitimidad a los discursos que determinan lo que debe ser considerado como conocimiento científico. Cuando se sostienen esas tradiciones epistemológicas sin establecer vínculos estrechos con las áreas disciplinares donde se enseña y se construye la adversidad, los/las estudiantes reciben una asignatura que suele estar separada de sus trayectorias académicas y que oscilan entre aportar perspectivas históricas y problemas generales de la ciencia comprendida como universal. Esa fragmentación que se produce en el aula, sumada a la incorporación de conceptualizaciones distantes de sus campos disciplinares no coopera en el aprovechamiento de los contenidos. Las cátedras de 
epistemología son imaginadas como los espacios curriculares para que los/las estudiantes desarrollen pensamiento crítico y reflexivo. Es un reto para docentes y estudiantes que dada las condiciones en las que se configura suele resultar en una seguidillas de sentimientos frustrantes. Estoy pensando en la necesidad de replantear la enseñanza de la epistemología y en la importancia de sumar los aportes de clase, religión, sexo-género para volver significativa una práctica de enseñanza-aprendizaje en tensión tanto con el contexto geopolítico como con el área disciplinar.

La reproducción del canon afecta a la producción de nuevos temas y problemas al conocimiento científico porque estos siguen sujetos a teorías eurocentradas, patriarcales, en vinculación con una parte de la academia universitaria que no está dispuesta a correr el riesgo de distanciarse de lo prescripto tradicionalmente como válido. La epistemología promueve el pensamiento crítico sobre el conocimiento científico, sin embargo hay áreas que aparecen veladas a la mirada y entonces estamos frente a la serpiente que se come su cola. La bibliografía escrita por mujeres no logra atravesar el muro infranqueable que reviste al espacio áulico y la pregunta sobre las razones que generan esa exclusión aparece inalterable.

A principio del siglo XX se produjo una rotación, una ruptura quizás, un desencanto de la razón que propició otro orden de significaciones. Hemos asistido al giro lingüístico, hemos entendido y practicado el giro de(des)colonial, entonces cuesta pensar en las razones por las que la epistemología clásica sigue sin poder apreciar la profunda relación existente entre el giro epistémico y el giro feminista. Emerge imperiosa la episteme adversa cuando pensamos en aulas donde las epistemologías que se dictan no reconocen o sitúan en una posición subalterna a las epistemologías feministas, o a las epistemologías provenientes de otras cosmovisiones que no sean la tradición heredada. A cambio, las epistemologías feministas, en todo su arco, han recorrido un largo camino y en ellas puede observarse una amplitud de conflictos que recuperan las tensiones intersticiales. Desde hace más de una década las autoras vienen advirtiéndolo, Haraway, Donna (1995); Harding, Sandra (1996); Bidaseca, Karina (2016); Maffía Diana (2007).

La expulsión de las mujeres en la ciencia (como en las otras construcciones culturales humanas) tiene un doble resultado: impedir nuestra participación en las comunidades epistémicas que construyen y legitiman el conocimiento, y expulsar las cualidades consideradas "femeninas" de tal construcción y legitimación, e incluso consideradas como obstáculos" (Maffía, 2007 p. 64). 
La estructura de poder que configura epistemes es patriarcal, porque las instituciones educativas universitarias están marcadas por esa tradición y viceversa. No es homogénea la trama institucional académica y en ella conviven voces disidentes que pugnan de múltiples modos por abrir espacios. Nuestras aulas están pobladas por estudiantes que hacen de su estar ahí una conflictividad activa. Hay algo en la subjetivación de ellos/ellas que se alterna entre el deseo por el conocimiento y las resistencias. Las prácticas áulicas de intercambio de conocimientos implican siempre un desacomodamiento de creencias y prejuicios preconcebidos. En el ejercicio de la práctica docente también suceden esos desfasajes entre lo proyectado y lo que finalmente acontece. No siempre esos estudiantes están en situación receptiva, hay momentos en que ese pacto inicial del espacio áulico favorece el intercambio educativo, quizás pase, pero quizá no. Cuando pienso en las relaciones de sexo/genérica presentes en las teorías feministas dentro del proceso pedagógico se habla de muchas cosas. Acuerdo con la descripción que hacen Fischetti y Alvarado (2015), propongo una cita de este trabajo que tiene que ver con lo que vengo exponiendo.

Es justamente en el sistema educativo donde muchas veces se gesta la ceguera que respalda la creencia convencional de que lo verdaderamente científico es lo que pueden controlar los métodos y que se produce en el contexto de justificación. Sin embargo, entendemos que es en el contexto de educación donde puede hacerse lugar a otros modos de producir conocimiento a los que la sujeto de enunciación les ponga el cuerpo gestando esa dimensión en la que se descubre, se identifican los problemas, se formulan las hipótesis y se definen las nociones, conceptos y categorías - esa dimensión excluida de lo «propiamente científico». (Fischetti, Alvarado, 2015, p. 180).

Estoy pensando en enfoques teóricos múltiples, incluso contrapuestos a veces, en prácticas socio-educativa, en enseñanza-aprendizaje, en procesos de apropiación y recreación de conocimientos. La dualidad heteronormada también está allí y sigue estando. Esos esquemas duales de conocimiento, deudores de la modernidad eurocéntrica conviven con epistemes y poéticas que implican cuerpos, afectaciones y territorios donde se habita y se producen los intercambios propios de lo educativo.

\section{APRENDER LA ADVERSIDAD}

En el centro del pensamiento epistemológico sobre el que estamos tratando de rondar, está la modernidad europea y están las meditaciones cartesianas con su legado Momento: diálogos em educação, E-ISSN 2316-3100, v. 28, n. 3, p. 113-131, set./dez, 2018. 
de sujeto solipsista. También está aquél hombre con mayúscula y solitario cognoscente aludido en toda la historia de la filosofía que funciona como universal ocultador de las diferencias. Las mujeres que hemos sido subsumidas por décadas en esa categoría "Hombre" nos negamos a seguir ubicándonos cómodamente en ella. Ser mujer, ser docente de epistemología, asumir el contexto geográfico del sur y los emergentes particulares de la tierra que pisamos construye una posición adversa hacia la cultura académica del conocimiento científico donde la reproductibilidad y el contexto de justificación son ponderados como valiosos. Un sujeto varón, solitario, se propone dar cuenta de la existencia de Dios (Descartes), otro varón solitario busca las condiciones de posibilidad para el conocimiento a través de la razón pura y enuncia la epistemología (Kant). Ese telón de fondo es lo adverso, en uno de sus matices, y es contra el que ejercemos nuestra labor. Están también allí esas construcciones conceptuales que nombramos como pensamiento eurocentrado, como neutralidad de la ciencia, como hegemonía del pensamiento occidental contra el que han expuestos argumentos autores como Quijano, 1999; Mignolo, 2010; De Oto, 2010; De Souza Santos 2009, por nombrar sólo algunos de los que en un gesto emancipatorio y emancipador están pensando desde América Latina.

Del otro lado del telón están las acciones enérgicas del pensamiento de Nuestra América y los diferentes giros que se han dado para poder pensarnos en la relación SurSur. A propósito de estas líneas el trabajo América Latina Hacia su segunda independencia (2007) porque allí se escriben caminos que no han dejado de desandarse y que después de una década nos permiten establecer puntos de unión entre los intereses de los giros que pueden ser seguidos a través de las publicaciones "El habla, la escritura y los sistemas de signos de distinto tipo, tanto como su conceptualización - con la distribución disciplinar del saber que las formalizan -, integran un conjunto de relaciones por las que la colonización se hace efectiva”. (Palermo, 2007, p. 299).

Quienes enseñamos epistemología e intentamos asumir la perspectiva feminista sospechamos de la "concepción heredada" como adversidad a la que nos hemos sobrepuesto de diversas maneras. Hemos recorrido el largo camino de la formación intelectual para luego desandarlo paso a paso en el revés de la carrera académica. Hemos caminado por los bordes en busca de sendas, explorado fronteras y huido de los centramientos. También, las mujeres hemos pasado por diversos procesos de reconfiguraciones y cuestionamiento como el que se describe en "Inscripciones feministas. Notas críticas sobre la reproducción del conocimiento" (2015) 
Nos preguntamos por un feminismo de cuño latinoamericano que interrogue al modelo de ciencia que atravesamos y que nos atraviesa. Nos preguntamos por la producción y la reproducción del conocimiento en la ciencia y en la educación desde la perspectiva de un feminismo crítico que hemos escuchado poco, casi nada, en una academia que parece reproducirse una y otra vez con caracteres estrictamente andrógenos, propios del capitalismo y el colonialismo. Nos preguntamos por un feminismo del que no encontramos libros en circulación ni en librerías ni en bibliotecas. Nos preguntamos por las posibilidades de que una perspectiva desde las voces de las mujeres vacíe y desborde los campos del saber, de producción y de reproducción del conocimiento. (Fischetti, Alvarado, 2015, p. 170).

Desanudar los nudos ciegos de los cruces de los caminos por la academia reclama examinar la relación de regiones argentinas que conversan en contrapunto desigual con los centros que imponen Buenos Aires, Rosario o Córdoba. Hay otras regiones donde se reproducen las mismas huellas de la academia universitaria, pero también hay preocupaciones específicas al contexto más próximo. La construcción geopolítica del conocimiento viene desplazándose de distintas maneras (Bidaseca, 2016; Bonavitta, Bard Wigdor 2018). Desaprender requiere un esfuerzo y representa un desafío. Pensar epistemes de la adversidad genera una semántica proteica que no carece de ambigüedades y sutilezas. Desandar sus huellas invita a revisar los pasados y trayectorias de formación académica, también es necesario estar atentas a las provocaciones que fueron abriéndose paso durante el tránsito del camino inverso. Verso, inverso, adverso pueden ser tres momentos que permiten ampliar los límites que quedan capturados dentro de los muros de las aulas.

Retomo dos fragmentos de autoras que no leí hasta terminar la carrera de grado, aquella carrera de filosofía que sólo estaba marcada a través del pensamiento de los varones que conforman el canon de la filosofía occidental. Aquél conocimiento que tuve que desandar para poder encontrarme con mi subjetividad intelectual por fuera del canon, para dejar de pensar como un varón europeo. Los años en la academia me des-formaron, me ofrecieron una trayectoria lineal eurocentrada escrita y pensada por cantidad de varones griegos, franceses, alemanes, ingleses, españoles, etc. La única excepción fue una asignatura dedicada a filosofía argentina y latinoamericana, aunque también estaba marcado por varones. No eran tiempos en los que la filosofía feminista pudiera atravesar las carreras de filosofía, como tampoco lo es en el presente donde la enseñanza sigue siendo androcéntrica. Es por esos movimientos de formación, des-formación, ampliación formativa y reconfiguración epistémica que pienso en las epistemologías adversas. Un primer trayecto formativo suscripto al canon filosófico, un segundo trayecto desanudando 
los condicionamientos heteronormativos, patriacales y eurocentrados, un tercer momento de ampliación formativa para conocer las teorías feministas y diversas que contemplan la inclusión no solo de las mujeres sino de otras personas que tampoco son representadas con la palabra Hombre. Es reciente la posibilidad de reconfigurar la posición epistémica en relación a las intersecciones que abren a horizontes críticos y vigilancias epistemológicas activas. Los dos fragmentos que evoco son de Esther Díaz (2010), Violeta Guyot (2005)

Se impone entonces replantearse los postulados de la epistemología, para que logre desarrollarse al ritmo marcado por el despliegue de la ciencia y de la técnica, y atienda así mismo a los problemas que se desprenden de la inserción de los productos científicos en la sociedad. Considero que ello representa un desafío para los teóricos de la ciencia y una obligación ética e intelectual para los profesionales de la educación" (Díaz, E. 2010, p. 168) "volver a plantear la pregunta "¿qué es lo que en el presente tiene sentido para una reflexión epistemológica, si no es el plantearse una línea de fuga cómo la única posibilidad de afrontar los desafíos de lo que somos en este preciso momento de la historia? (Guyot, V. 2005, p. 24).

\section{EPISTEMES ADVERSAS}

Las epistemologías adversas requieren ser pensadas desde la polisemia. Pueden evocar posiciones contrahegemónicas, pero también espacios difusos donde lo adverso es también una oportunidad para que otras epistemes encuentren un cauce fecundo. Se abren desafíos ante condiciones de imposibilidad para la producción de conocimientos donde lo adverso es un espacio simbólico que se construye a contrapelo de la misma producción académica que niega la legitimidad epistémica de algunas epistemes. Entre otras preguntas que afloran desde las epistemes adversas están las que tienen que ver con la transversalidad en relación con el género y los conocimientos. También está presente la necesidad teórica de enunciar la pluralidad en los enunciados que interpelan las fases de producción y aplicación de los conocimientos en los circuitos académicos. Las epistemologías adversas dan cuenta de polisemia y diversidad que desde el lenguaje interpelan los modos unívocos de hablar de conocimiento científico. De la misma manera se imponen interrogantes sobre los modos en que se imbrican y yuxtaponen las tramas disciplinares en torno a los nuevos modos de producir conocimiento en los que los bordes de las disciplinas se mixturan. No es posible hablar de unidad ni linealidad en el conocimiento científico, en cambio la adversidad epistémica pugna por nuestras construcciones que divergen.

Las aulas universitarias son espacios adversos, en los que la construcción del 
conocimiento epistemológico se genera en la incomodidad. Los planes de estudio regulan e indican contenidos para esos espacios curriculares que dan cuenta de una cultura académica de otras épocas, desfasada. La ciencia ya no es la misma ciencia en la que pensaba la "concepción heredada", pero tampoco los contextos de descubrimiento, justificación y aplicación son los mismos en los que la "ciencia pura y la aplicada" producen certezas. Las decisiones sobre los autores de esos materiales, para el trabajo áulicos, son fundantes de sentido en el proceso de enseñanza-aprendizaje y de producción-reproducción del conocimiento epistémico. Quienes elegimos autores para diseñar planificaciones operamos una acción política insoslayable. En esas decisiones puede haber resistencia, reproducción o disidencia. Hay adversidad porque las tensiones se hacen presentes en la subjetividad de la práctica docente. Las mujeres estamos habituadas a leer a varones, pero la operación inversa es escasa. Las condiciones de conocimiento científico han roto su anclaje a una pretensión de conocimiento universal. Los supuestos de unicidad y universalidad del conocimiento ya no responden a demandas específicas de ciencia aplicada. En estos últimos, la relación de ciencia producida a escala global no coincide con las concepciones de universalidad hasta hace poco tiempo sostenidas por la tradición. La producción a escala global de la ciencia se compone a través redes donde la fragmentación de la producción de los conocimientos (las condiciones que lo hace posible) y la integración en centros de control económico que puedan financiar los trabajos han resituado las concepciones sobre conocimiento científico (Kreimer, 2017, 2015). En ese sentido la relación entre lo regional y lo global ha resignificado la construcción geopolítica del conocimiento sosteniendo la subalternidad tensa que no coincide con la idea de universalidad.

Por ello "hacer bien las cosas" ya no significaba someterse a las reglas de la ciencia básica o aplicada, sino en desplazar las prioridades temáticas y objetivos impuestos desde lógicas externas provenientes del sistema internacional y atraer financiación hacia los temas relacionados a problemáticas regionales relevantes. Dicha categoría coincidió con la utilizada por los científicos en Santa Fe de "trabajar con ciencia" en nichos originales pero de "segunda línea" y de abstenerse de competir en temas seleccionados por la comunidad internacional. (Stangnaro, 2017, p. 291)

Las preguntas sobre el contexto de descubrimiento y aplicación tienen otros horizontes de sentidos. Las relaciones entre geopolítica, feminismos y epistemologías editan una serie de cuestionamientos al conocimiento científico que reclaman desprendimientos urgentes de concepciones tradicionales sobre las epistemes. 
Los contextos de descubrimiento muestran rápidamente la subalternización de los/las científicas por parte de redes científicas con mayores potenciales económicos para financiar las investigaciones. Los problemas epistemológicos posibles de ser discutidos en las aulas cambian el tono si se incluyen las condiciones de producción y descubrimiento científico. Para los/las estudiantes, dar cuenta de esa fase equivale a desarrollar pensamiento crítico. En ese sentido los factores que desfavorecen la ciencia situada son insumos prácticos para el pensamiento.

En estos nuevos escenarios académicos, la inserción de autores/as feministas resulta adversas al sistema patriarcal no solo porque reivindican un lugar para sus voces y cuerpos sexo-genéricamente identificados como diversos, sino porque en ese mismo gesto otras cuestiones son reclamadas. Se desvelan cambio en la jerarquización epistémica y resulta evidente la necesidad de inclusión de otras voces que han quedado excluidas además de las relacionadas con el género como pueden serlo las epistemes de saberes originarios, cosmovisiones situadas en tradiciones de personas migrantes, sexualidades disidentes, entre otras. Están sucediendo cambios profundos en la manera de incluir otras epistemes como los que da cuenta Bidaseca, K. (2016) con una de las tantas línea de trabajo "Feminismos y (des) colonialidad. Las voces de las mujeres indígenas del sur". Las cartografías sobre feminismos del sur y epistmes vinculadas a estos movimientos están ayudando a una mayor comprensión del estado actual de la cuestión. Campagnoli (2018) escribe un mapeo sobre las principales líneas que pueden ser observadas para pensar las epistemologías feministas y estas permiten "comprender que la producción de estas perspectivas se realiza en, con e incluso contra el saber académico, en la modalidad de una praxis donde no habría fronteras claras entre academia, militancia y activismo" (Campagnoli, 2018. p. 3). Otra mirada aporta Laura Catelli desde el campo de los estudios coloniales que es recuperada por otras autoras en relación con el feminismo. También contribuyen, entre otras tantas autoras que podrían ser mencionadas, desde el pensamiento feminista de Abya Yala Gabriela Bard Wigdor y Paola Bonavitta (2018) y en la exploración de nuevos cruces entre metodologías y epistemes, Mariana Guerra Pérez (2018).

\section{CONSIDERACIONES FINALES}

La tierra que pisamos y en la que producimos conocimientos demanda epistemes adversas capaces de motivar el proceso de enseñanza/aprendizaje en contextos Momento: diálogos em educação, E-ISSN 2316-3100, v. 28, n. 3, p. 113-131, set./dez, 2018. 
adversos. Los materiales que seleccionamos para cada asignatura se ven atravesados por problemas que la ciencia ha sabido excluir. La inclusión de autoras y de trabajos sobre epistemologías feministas que no vemos en abundancia en los programas de estudio recuerda la exclusión. Esos muros infranqueables quizás no dejan pasar a las autoras, pensamos, por razones que a las mujeres nos resultan evidentes. Algunas de ellas pueden estar relacionadas con la notable interpelación que las corrientes feministas han ejercido a la cultura occidental en la que la construcción masculina de la cultura, la ciencia y las academia han fraguado la exclusión no sólo de las mujeres sino de todo lo que no coadyuvara a la heternomatividad que aún persiste de manera notable (Harding, S. 1986); (Mafia, M. 2007). Esas interpelaciones tienen recepciones moderadas por parte de la academia que sigue ejerciendo la indiferencia como mecanismos de exclusión privilegiado. Otras razones pueden estar relacionadas con la amplitud de los trabajos que provienen de los feminismos y que requieren dedicación para la comprensión. Los trabajos que desde las perspectivas de género se han producido en los últimos años y que dan cuenta de corriente de pensamiento también tienen sus disputas hacia el interior del nuevo campo de estudio y en general no resulta sencillo abordarles.

\section{REFERENCIAS}

Bachelard, G. (2000). La formación del espíritu científico. Siglo XXI.

Bard Wigdor, G. y Artazo, G. (2017). Pensamiento feminista Latinoamericano: Reflexiones sobre la colonialidad del saber/poder y la sexualidad. Cultura representaciones soc [online]. 2017, 11(22), p.193-219.

Bard Wigdor, G. B., \& Bonavitta, P. (2018). Poesía de nuestra AméricaPresentación. RevIISE-Revista de Ciencias Sociales y Humanas, 11(11), 329-330.

Benavídez, A.; Guerra Pérez, M. (2017) La herida epistémica feminista. Te leo mientras atajo. III Coloquio Internacional Pensamiento Crítico del Sur. Lugar: Mendoza.

Biagini, H. E y Roig A. A. (Comps.). América Latina Hacia su segunda independencia, Aguilar, Alfaguara. Edición digital. Recuperado de: www.cecies.org/imagenes/ediciones 122.pef, 2007.

Bidaseca, Karina (coord.) (2016). Genealogías críticas de la colonialidad en América Latina, Áfica, Oriente. Bs As: CLACSO.

Bidaseca, K., \& Laba, V. V. (2016). Feminismos y (des) colonialidad. Las voces de las mujeres indígenas del sur. Temas de Mujeres, 7(7). 
Bidaseca, K. (2014). Cartografías descoloniales de los feminismos del sur. Revista de Estudos Feministas, Florianópolis, UFSC, 22(2), 585-591.

Campagnoli, M. A. (2018). Epistemologías críticas feministas. Aproximaciones actuales. Descentrada. 2 (2), e047. Recuperado de:

http://www.descentrada.fahce.unlp.edu.ar/article/view/DESe047.

Castro-Gómez, S. (1998). Latinoamericanismo, modernidad, globalización.

Prolegómenos a una crítica poscolonial de la razón. Teorías sin disciplina.

Latinoamericanismo, poscolonialidad y globalización en debate, 169-205.

Catelli, Laura (2012). "Introducción: ¿Por qué estudios coloniales latinoamericanos?:

Tendencias, perspectivas y desafíos actuales de la crítica colonial”. Cuadernos del

CILHA, 13(2), 4556. Argentina. Recuperado de

: http://www.scielo.org.mx/scielo.php?script=sci nlinks\&pid=S2007-

$8110201700010019300009 \& \ln \mathrm{g}=\mathrm{en}$.

De Oto, A. (2010). Pensamiento descolonial/decolonial. Proyecto: Diccionario del pensamiento alternativo II. Pensamiento latinoamericano y alternativo. Cecies.

Recuperado de: http://www. cecies. org/articulo. asp.

De Sousa Santos, B. (2009). Una epistemología del sur: la reinvención del conocimiento y la emancipación social. Siglo XXI.

De Sousa Santos, B. (2010). Refundación del Estado en América Latina: Perspectivas desde una epistemología del Sur. Plural editores.

Diaz, E. (2010). El rigor científico y sus consecuencias biopolíticas como propedéutica para una filosofía de la educación. Educação Unisinos, 14(3), 167-173.

Fischetti, N., \& Alvarado, M. (2015). Inscripciones feministas. Notas críticas sobre la (re) producción del conocimiento. Revista venezolana de estudios de la mujer, 20(45), 165-184.

Gargallo, F. (2015). Feminismos desde Abya Yala: ideas y proposiciones de las mujeres de 607 pueblos en nuestra América. Universidad Autonoma de la Ciudad de México.

Gargallo, F. (2008). "El feminismo y la educación en y para Nuestra América", en Revista venezolana de estudios de la mujer, Caracas, Vol. 13, n. 31, julio-diciembre de 2008, pp. 17-26. Recuperado de: https://francescagargallo.wordpress.com/.

Guerra Pérez, M. (2018). "Notas para una metodología de investigación feminista decolonial. Vinculaciones epistemológicas". Religación. Revista de Ciencias Sociales y Humanidades, Quito, 3, p. 90-101.

Guyot, V. (2005) "Epistemología y prácticas del conocimiento". Ciencia, Docencia y Tecnología $\mathrm{N}^{\mathrm{o}} 30$, Año XVI, mayo de 2005, 9-24. Recuperado de:

http://www.revistacdyt.uner.edu.ar/articulos/descargas/cdt30_guyot.pdf.

Haraway, D. (1995, [1991]). Ciencia, cyborgs y mujeres. La reinvención de la 
naturaleza. Madrid: Cátedra.

Harding, S. (1996, [1986]). Ciencia y feminismo. Madrid: Morata.

Korol, C. (2017) "Cuerpos y territorios. Las mujeres en la defensa de la vida diversa y de la libertad" en Memorias de las III Jornadas Nacionales de Ecología Política I Graciela Pastrán [et al.]; coordinación general de Mariana Martinelli; Mariángeles Gaviorno; Marisel Inojosa. - 1a ed. - San Juan: Editorial UNSJ, 2017.

Klimovsky, G. (1995). Las desventuras del conocimiento científico. Una introducción a la epistemología. Bs. As.: AZ editores.

Kriemer, P. (2016) "Contra viento y marea en la ciencia periférica: niveles de análisis, conceptos y métodos". Contra viento y marea: emergencia y desarrollo de campos científicos en la periferia: Argentina, segunda mitad del siglo XX/Pablo Kreime [et al.]; editado por Pablo Kreimer. $1^{a}$ ed. Ciudad Autónoma de Buenos Aires: CLACSO, 2016.

Kreimer, P. (2015). Los mitos de la ciencia: desventuras de la investigación, estudios sobre ciencia y políticas científicas. Nómadas, (42), p. 33-51.

Kreimer, P. (2017). Los estudios sociales de la ciencia y la tecnología:¿ son parte de las ciencias sociales?. Teknokultura, 14(1), 143-162.

Kant, I. (2009). Crítica de la razón pura. Ediciones Colihue SRL.

Lander, E. (2000). La colonialidad del saber: eurocentrismo y ciencias sociales. Perspectivas latinoamericanas. Buenos Aires: CLACSO.

Maffía, Diana (2007). Epistemología feminista: La subversión semiótica de las mujeres en la ciencia. Revista venezolana de estudios de la mujer, 12(28).

Machado Araoz, H. (2017). "Conferencia Inaugural" en Memorias de las III Jornadas Nacionales de Ecología Política. (1a ed.), San Juan: Editorial UNSJ, 2017.

Mignolo, W. (2010). Desobediencia epistémica: retórica de la modernidad, lógica de la colonialidad y gramática de la descolonialidad. Ediciones del signo.

Palermo, Z. (2007). Desafíos éticos para la Universidad Latinoamericana del futuro. América Latina hacia su segunda independencia. Memoria y autoafirmación, p. 297-308.

Quijano, A. (1999). Colonialidad del poder, cultura y conocimiento en América Latina. Dispositio, 24(51), 137-148.

Reichenbach, H. (1938). Experience and prediction: An analysis of the foundations and the structure of knowledge.

Spivak, G. C. (1988). Can the subaltern speak?. Can the subaltern speak? Reflections on the history of an idea, 21-78. 
Stagnaro, A. (2015). Ciencia a pulmón: etnografías de laboratorios argentinos de biotecnología. Ediciones CICCUS.

Torrano, A., \& Fischetti, N. (2018). Apuestas del feminismo:

Ciencia/Técnica/Latinoamérica. Nuevas urdimbres desde el Sur. RevIISE-Revista de Ciencias Sociales y Humanas, 11(11), 267-279.

Torres González, O., \& Pau, B. (2011). "Techo de cristal'y" suelo pegajoso': La situación de la mujer en los sistemas alemán y español de ciencia y tecnología. Revista iberoamericana de ciencia tecnología y sociedad, 6(18), 35-59. 